\title{
ANALISIS CUACA PADA SAAT PELAKSANAAN TMC PENANGGULANGAN BANJIR JAKARTA JANUARI FEBRUARI 2014
}

\author{
Erwin Mulyana ${ }^{1}$ \\ erwin6715@yahoo.com \\ Badan Pengkajian dan Penerapan Teknologi
}

\begin{abstract}
Application of weather modification has carried out to reduce precipitation over Jakarta on 11 January to 14 February 2013. During this period, El Nino Southern Oscillation and Indian Ocean Dipole Mode were normal condition. The Madden Julian Oscillation shows that the convection over Indonesia region was netral condition. The sea surface temperature over west part of Java waters was $29-3029^{\circ} \mathrm{C}$. The $850 \mathrm{mb}$ average of relative humidity on mid January mid February 2014 was $70-80 \%$. Based on visual and weather radar observation, cloud development mainly over northwest to southwest of Jakarta. Positive Australian Summer Monsoon Index affected to increase precipitation over Java area.
\end{abstract}

Key words : flood, weather modification, ENSO, IOD, SST, Australian Summer Monnsoon Index.

\begin{abstract}
Abstrak
Pada tanggal 11 Januari sampai dengan 14 Februari 2014 telah dilaksanakan penerapan teknologi modifikasi cuaca (TMC) untuk menanggulangi banjir di wilayah Jakarta dan sekitarnya. Selama kegiatan tersebut fenomena ENSO dan IOD dalam kondisi normal. MJO menunjukkan aktifitas konvektif netral di wilayah Indonesia pada pertengahan Januari hingga pertengahan Februari 2014. Temperatur permukaan laut di perairan Jawa bagian barat sekitar 28-29 C. Kelembagan udara pada level $850 \mathrm{mb}$ sekitar 70-80\%. Pertumbuhan awan umumnya berada di sebelah barat daya, barat dan barat laut Jakarta. Indeks Monsoon Australia positif berpengaruh terhadap peningkatan pembentukan awan hujan di Jawa.
\end{abstract}

Kata kunci : banjir, teknologi modifikasi cuaca, ENSO, IOD, SST, indeks monsun Australia. 


\section{PENDAHULUAN}

Iklim Indonesia sangat dipengaruhi oleh system monsoon Asia-Australia (Ramage, 1968). Penyimpangan iklim yang terjadi di Indonesia diantaranya berhubungan dengan ENSO (EI Nino Southern Oscillation) dengan perulangan antara 4 hingga 7 tahun. ENSO berpengaruh terhadap kekeringan akibat musim kemarau yang lebih lama dari biasanya (Ropelewski dan Halpert, 1989; Kane, 1997, Hamada, 1995; Aldrian, 2002; Mulyana, 2002). Perubahan temperatur permukaan laut di Samudera Hindia yang dikenal dengan Dipole Mode (IOD) juga berpengaruh terhadap curah hujan di Indonesia (Saji et.al., 1999; Mulyana, 2002). Faktor lain yang mempengaruhi iklim adalah Osilasi Maden Julian (Seto. T.H., 2002). Periode Maden Julian (MJO) berkisar antara 40 hingga 50 harian, sehingga berpengaruh terhadap variasi curah hujan dalam satu musim. Perubahan suhu muka laut di sekitar pulaupulau besar nusantara juga berpengaruh terhadap cuaca dan iklim di Indonesia.

Pola iklim di Indonesia dapat dibagi menjadi tiga macam yaitu pola monsoon, pola ekuatorial dan pola lokal (Aldrian dan Susanto, 2003). Pola Monsoon dicirikan oleh bentuk pola hujan yang memiliki satu puncak musim hujan. Selama tiga bulan curah hujan relatif tinggi yang dikenal dengan musim hujan, yakni Desember, Januari dan Februari (DJF) dan tiga bulan curah hujan rendah disebut musim kemarau pada periode Juni, Juli dan Agustus (JJA). Sedangkan enam bulan sisanya merupakan periode peralihan yaitu tiga bulan peralihan kemarau ke hujan (SON), dan tiga bulan peralihan hujan ke kemarau (MAM).

Pola ekuatorial dicirikan oleh pola hujan yang memiliki dua puncak hujan, biasanya terjadi sekitar bulan Maret dan Oktober yaitu pada saat matahari berada dekat ekuator. Sedangkan Pola lokal dicirikan oleh bentuk pola hujan yang memiliki satu puncak hujan akan tetapi bentuknya berlawanan dengan pola hujan pada tipe monsoon.

Pola hujan di wilayah Jakarta dan sekitarnya termasuk pola monsoon dengan musim hujan pada bulan Desember-Februari dan musim kemarau pada bulan Juni-Agustus. Pada musim hujan inilah, wilayah Jakarta dan sekitarnya selalu mengalami banjir baik dalam sekala besar maupun sekala kecil.

Banjir besar di wilayah Jakarta pernah terjadi pada tahun 2002 dan 2007 yang mengakibatkan korban jiwa dan kerugian ekonomi yang sangat besar. Pertengahan bulan Januari 2013 terjadi banjir di Jakarta, begitu juga pada bulan Januari 2014 terjadi lagi banjir di Jakarta walaupun tidak sebesar banjir pada tahun sebelumnya. Untuk mengurangi intensitas hujan di wilayah Jakarta dan sekitarnya, telah dilakukan upaya penerapan teknologi modifikasi cuaca (TMC)
Tulisan ini merupakan hasil kajian cuaca selama kegiatan TMC dalam penanggulangan banjir Jakarta yang dilaksanakan di wilayah Jakarta dan sekitarnya pada tanggal 14 Januari sampai dengan 11 Februari 2014.

\section{DATA}

Data yang digunakan dalam tulisan ini berupa data global dan regional yang berpengaruh terhadap cuaca di Indonesia serta data pengamatan cuaca di beberapa stasiun meteorologi di sekitar wilayah Jakarta. Data global dan regional meliputi temperatur permukaan laut (SST) di Samudera Pasifik, Samudera Hindia, perairan Indonesia, angin gradient serta keberadaan siklon tropis yang terjadi di sekitar wilayah Indonesia.

\section{HASIL DAN DISKUSI}

Kondisi cuaca selama kegiatan pelaksanaan TMC dari tanggal 14 Januari s.d. 11 Februari 2014 di wilayah DKI Jakarta dan sekitarnya, umumnya sangat dipengaruhi oleh kondisi global/regional dan lokal.

Kondisi global/regional yang dominan pengaruhnya terhadap cuaca di Jakarta dan sekitarnya adalah perbedaan suhu permukaan laut di Samudra Hindia bagian barat dan bagian timur yang disebut dengan IOD (Indian Ocean Dipole) serta massa udara yang datang ke wilayah Jakarta dan sekitarnya. Faktor lain yang berpengaruh terhadap pembentukan awan hujan di wilayah Jakarta dan sekitarnya adalah fenomen ENSO (El Nino Southern Oscilation) dan MJO (Maden Julian Oscillation) serta gangguan tropis berupa tropical depression hingga tropical cyclon yang terjadi di Samudera Hindia sebelah barat daya Sumatera hingga sebelah selatan Jawa, maupun di Samudera Hindia sebelah barat laut Australia. Sirkulasi monsun Asia-Australia, daerah pertemuan angin antar tropis atau Inter Tropical Convergence Zone (ITCZ) yang merupakan daerah pertumbuhan awan, serta suhu permukaan laut di sekitar wilayah Indonesia juga berpengaruh terhdadap cuaca dan iklim di wilayah Jakarta dan sekitarnya.

Variasi topografi berupa pegunungan di sebelah selatan Jakarta seperti di Bogor dan sekitarnya mengakibatkan pembentukan awan orografik dominan di daerah tersebut, sedangkan di bagian utara yang berupa dataran rendah didominasi oleh pembentukan awan konvektif.

\subsection{Temperatur Permukaan Laut}

Temperatur permukaan laut di perairan Indonesia maupun di Samudra Pasifik dan di Samudera Hindia berpengaruh terhadap pembentukan awan dan kejadian hujan di wilayah Jakarta dan sekitarnya. Pantauan fenomena ENSO dan IOD memberikan informasi mekanisme global/regional yang berpengaruh terhadap 
pembentukan awan dan kejadian hujan di wilayah Jakarta dan sekitarnya.

ENSO dengan skala temporal antar-tahun mempengaruhi aktifitas pembentukan awan dan hujan secara global. Sementara kondisi topografi yang bergunung di wilayah selatan Jakarta, serta dataran rendah di wilayah utara merupakan fenomena lokal yang menambah beragamnya kondisi iklim di wilayah Jakarta dan sekitarnya, baik menurut ruang maupun waktu.

Temperatur permukaan laut di Pasifik equator bagian tengah hingga akhir Februari 2013 masih di kisaran normal. Sementara IOD di Samudera Hindia juga menunjukkan kondisi netral. Perubahan temperatur permukaan laut hingga pertengahan Februari 2014 di daerah Nino 3.4 ditunjukkan pada Gambar 1, sedangkan untuk IOD diperlihatkan pada Gambar 2.

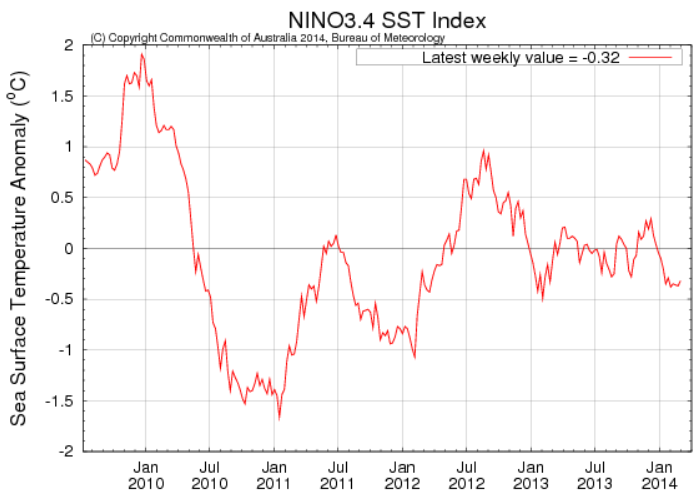

Gambar 1. Grafik Anomali SST di Nino 3.4 sampai pertengahan Februari 2014 yang menunjukkan kondisi ENSO netral. (http://www.bom.gov.au/climate/enso/indices.s

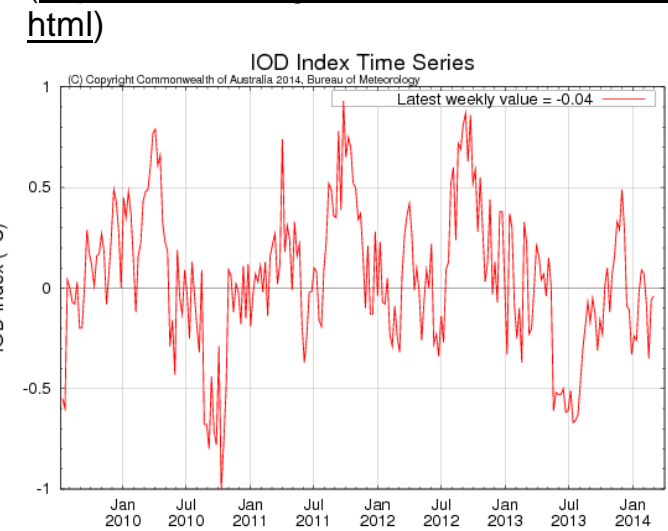

Gambar 2. Grafik IOD sampai pertengahan Februari 2014 yang menunjukkan kondisi netral.

bom.gov.au/climate/enso/indices.shtml)

Sementara suhu permukaan laut di perairan Indonesia dan sekitarnya berkisar 26-30 ${ }^{\circ} \mathrm{C}$. Suhu permukaan laut di sebelah barat dan selatan Jawa sekitar $29{ }^{\circ} \mathrm{C}$, sedangkan di Laut Jawa temperaturnya lebih rendah yaitu sekitar $28{ }^{\circ} \mathrm{C}$. Hangatnya kondisi laut di sebelah barat dan selatan Jawa mengakibatkan uap air di daerah tersebut cukup tinggi sehingga awan hujan mudah terbentuk. Uap air tersebut juga bergerak ke arah timur terbawa oleh angin baratan dan masuk ke wilayah Jabodetabek dan sekitarnya membentuk awan hujan di daerah tersebut. Sebaran rata-rata temperatur permukaan laut dari tanggal 14 Januari s.d 15 Februari 2014 di perairan Indonesia dan sekitarnya ditunjukkan pada Gambar 3.

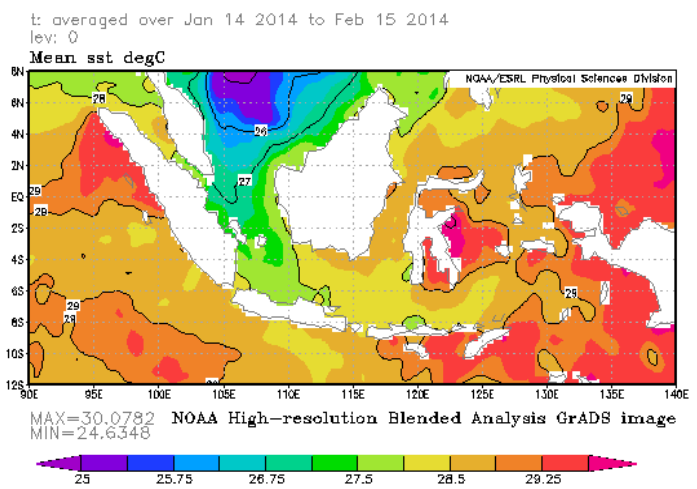

Gambar 3. Rata-rata temperatur permukaan laut di perairan Indonesia dan sekitarnya tanggal 14 Januari s.d 15 Februari 2014. (Sumber : NOAA/ESRL PSD)

\subsection{Madden Julian Oscillation}

Madden Julian Oscillation (MJO), merupakan salah satu variabilitas semusim yang terjadi di daerah tropis dan pertama kali diungkapkan oleh Rolan A. Madden dan Paul R. Julian (1971). Osilasi Madden Julian diasosiasikan dengan anomali konveksi khususnya pada daerah yang mempunyai suhu permukaan laut yang tinggi di antara Samudera Hindia dan Samudera Pasifik bagian barat. Osilasi ini bergerak ke arah timur antara $10^{\circ}$ LU dan $10^{\circ}$ LS dari Samudera Hindia menuju Samudera Pasifik dengan osilasi antara 40 sampai 50 hari.

Selaam kegiatan TMC berlangsung, fenomena MJO menunjukkan kondisi netral untuk wilayah Indonesia pada bulan Januari hingga Februari 2014. Monitoring MJO diperlihatkan pada Gambar 4. 


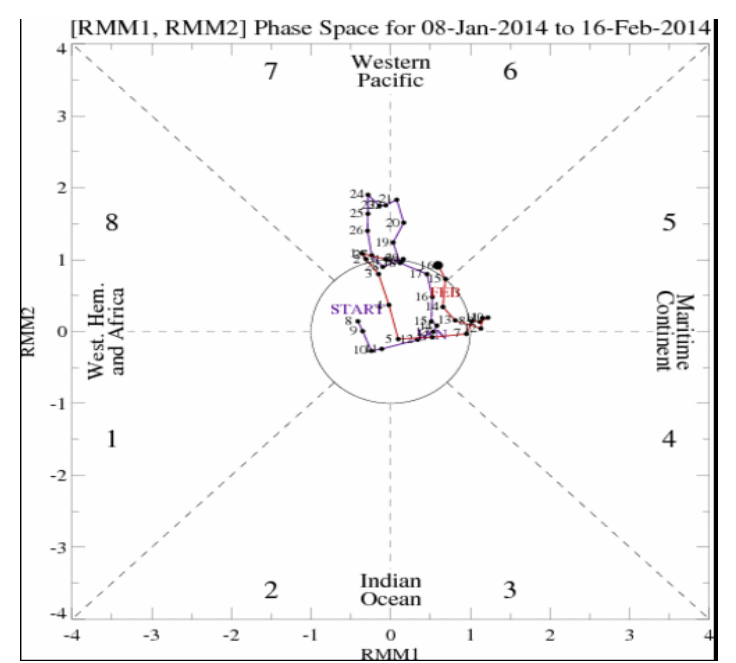

Gambar 4. Pergerakan MJO periode 8 Januari - 16 Februari 2014. (Sumber dari MaddenJulian Oscillation: Recent Evolution, Current Status and Prediction by Climate Prediction Center).

\subsection{Kelembaban Udara}

Kelembaban udara rata rata pada lapisan 850 $\mathrm{mb}$ dari tanggal 14 Januari sampai dengan 15 Februari 2014 di wilayah Jawa bagian barat berkisar antara $75-80 \%$. Hal ini menunjukkan bahwa secara umum kondisi atmosfer sangat mendukung terjadinya pembentukan awan hujan di daerah Jawa bagian barat khsusunya di wilayah Jabodetabek dan sekitarnya. Sebaran rata rata kelembaban udara tanggal 14 Januari s.d 15 Februari 2014 di wilayah Indonesia pada lapisan 850 mb ditunjukkan pada Gambar 5.

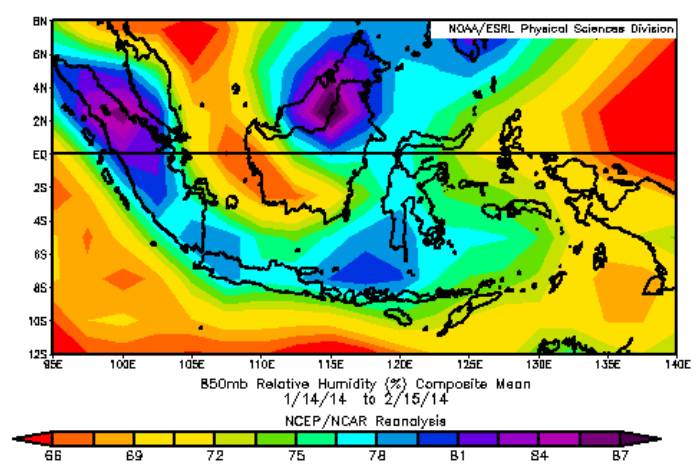

Gambar 5. Kelembaban udara di lapisan 850 $\mathrm{mb}$ tanggal 14 Januari s.d 15 Februari 2014. (Sumber : NOAA/ESRL PSD).

\subsection{Tekanan Udara dan Angin}

Selama berlangsungnya kegiatan TMC, angin di wilayah Jawa bagian Barat dominan dari arah barat, barat laut hingga barat daya. Kecepatan angin pada lapisan $850 \mathrm{mb}$ di wilayah tersebut berkisar antara 7 $8 \mathrm{~m} / \mathrm{s}$ atau sekitar $13-15$ knot. Pusat tekanan rendah beberapa kali muncul di wilayah Australia utara dan di wilayah sekitar Filipina. Pusat tekanan rendah yang berada di sekitar Filipina bertahan cukup lama karena posisinya hampir tidak bergeser dan sempat tumbuh menjadi badai tropis namun tidak terlalu kuat. Contoh pola tekanan udara di wilayah Indonesai dan sekitarnya ditunjukkan pada Gambar 6. Sedangkan pola kecepatan angin selama kegiatan TMC diperlihatkan pada Gambar 7.

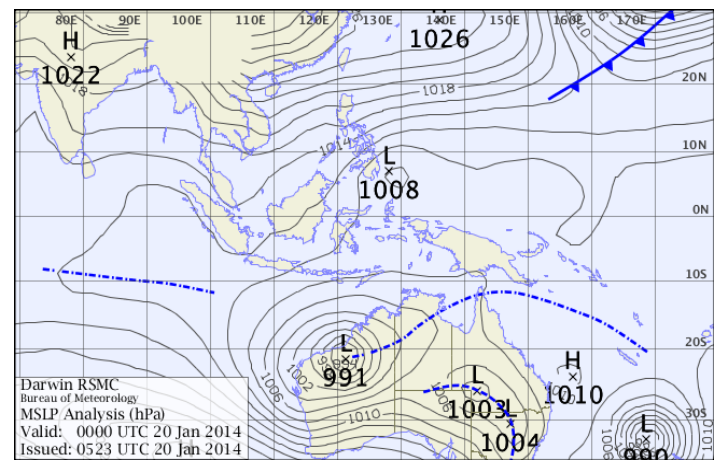

Gambar 6. Mean Sea Level Pressure tanggal 20 Januari 2014 jam 00.00 UTC. Pusat tekana rendah di Filipina dan pantai Barat Australia mempengaruhi pola aliran udara yang masuk ke Jawa. (Sumber: BOM, Australia).

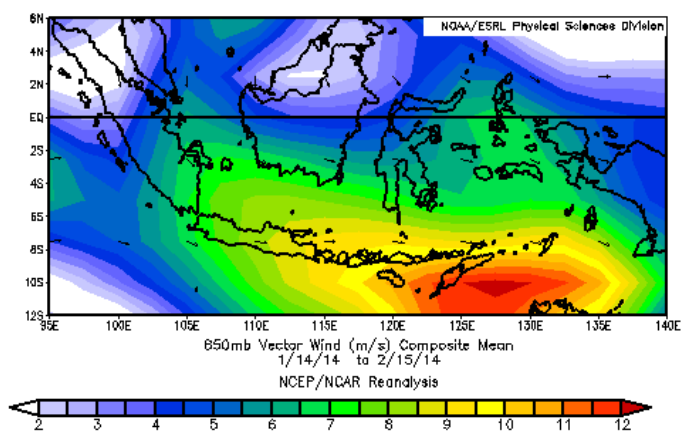

Gambar 7. Sebaran kecepatan angin level 850 mb tanggal 14 Januari s.d 15 Februari 2014. (Sumber : NOAA/ESRL PSD).

Umumnya daerah Pertemuan Angin Antar Tropis atau Inter Tropical Convergence Zone (ITCZ) membentang mulai dari Sumatera, Jawa hingga Nusa Tenggara. Gambar 8 adalah Gradient winds analysis tanggal 19 Januari 2014 jam 12.00 UTC yang menunjukkan pola konvergensi massa udara terjadi di wilayah Jawa hingga Nusa Tenggara. Sedangkan daerah liputan awan nampak pada contoh Gambar 9 dimana keberadaan awan cukup merata di perairan sebelah selatan Jawa, daratan Jawa bagian tengah dan bagian barat serta di Laut Jawa bagian barat. 


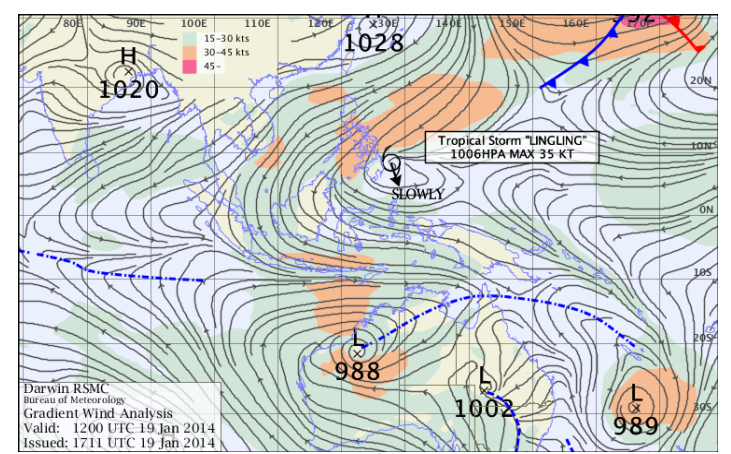

Gambar 7. Gradient winds analysis tanggal 19 Januari 2014 jam 12.00 UTC. ITCZ berada di Jawa sampai Nusa Tenggara. (Sumber: BOM, Australia).

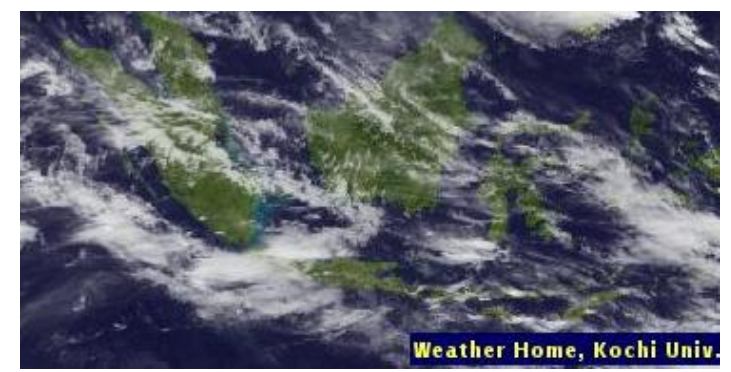

Gambar 8. Citra satelit tanggal 19 Januari 2014, jam 07:00 UTC. (Sumber: http://www.jma.go.jp/en/gms/index.html )

\subsection{Monsoon Australia}

Iklim di Indonesia juga sangat dipengaruhi oleh monsoon. Berdasarkan Australian Summer Monsoon Indext (AUSMI), terjadi peningkatan indek AUSMI pada pertengahan Januari hingga pertengahan Februari 2014. Fenomena meningkatnya AUSMI ini diduga berhungan dengan meningkatnya curah hujan di Jawa. Gambar 9 adalah grafik harian AUSMI hingga awal Maret 2014.

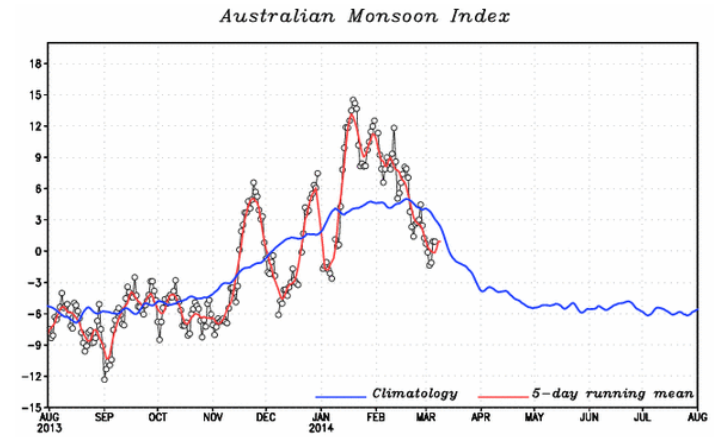

Gambar 9 Perubahan harian AUSMI hingga awal Maret 2014. (Sumber: Monsoon monitoring, APDRC).

\subsection{Cuaca Lokal}

Berdasarkan pengamatan cuaca dari pos meteorologi dan radar cuaca, secara umum angin permukaan di wilayah Jakarta dan sekitarnya bertiup dari barat daya - barat laut. Kondisi atmosfer dan temperatur permukaan laut yang hangat sangat mendukung pembentukan awan hujan di wilayah DKI Jakarta.

Pantauan radar menunjukkan umumnya pembentukan awan konvektif berada di sebelah barat laut, barat hingga barat daya daerah target. Sedangkan di sebelah selatan yang berupa dataran tinggi pembentukan awan lebih dominan akibat efek orografis sehingga secara klimatologis, curah hujan daerah wilayah tersebut relatif lebih banyak dibandingkan dengan di wilayah lainnya.

\section{KESIMPULAN DAN SARAN}

Selama kegiatan penanggulangan banjir di wilayah Jakarta dan sekitarnya melalui penerapan TMC dapat disimpulkan sebagai berikut :

1. Temperatur permukaan laut di perairan Jawa sekitar $28-29^{\circ} \mathrm{C}$ dengan kelembanan udara pada level $850 \mathrm{mb}$ sekitar $70-80 \%$. ENSO dan IOD dalam kondisi normal.

2. Area pertemuan angin antar tropis (ITCZ) berada di sekitar Laut Jawa hingga nusa tenggara. Angin baratan mendominasi wilayah Jakarta dan sekitarnya.

3. Pertumbuhan awan hujan umumnya berada di sebelah barat daya, barat, dan barat laut Jakarta..

4. Indeks Monsoon Australia positif, berpengaruh terhadap peningkatan pembentukan awan hujan di Jawa.

\section{DAFTAR PUSTAKA}

Aldrian. E., 2002 : Spatial Pattern of ENSO Impact on Indoensia Rainfall, Jurnal Sains dan Teknologi Modifikasi Cuaca, Vol. 3, No. 1, p. 5-15.

Aldrian, E. and, R.D. Susanto, 2003, : Indentification of the Three Dominant Rainfall Regions within Indonesia and their Relationship to Sea Surface Temperature, International Journal of Climatology, 23, 1435-1452.

Hamada, J.I., 1995 : Climatological Studi on rainfall Variation In Indonesia. Master Thesis, Kyoto Univ.

Kane, R.P., 1997 : Relationship of El Nino-Southern Oscillation and Pacific Sea Surface Temperature with Rainfall in Various Region of the Globe, Mon, Wea. Rev., 125, 1792-1800.

Madden R.A. and P.R. Julian, 1971. Description of a 40-50 day Oscillation in the Zonal Wind in the Tropical Pacific, J. Atmos.Sci., 28, 702-708.

Mulyana. E., 2002 : Hubungan ENSO dengan Variasi Curah Hujan di Indonesia, Jurnal Sains dan Teknologi Modifikasi Cuaca, Vol. 3, No. 1, p. 1-4.

---------, 2002 : Pengaruh Dipole Mode terhadap Curah Hujan di Indonesia, Jurnal Sains dan 
Teknologi Modifikasi Cuaca, Vol. 3, No. 1, p. 3943.

Ramage, C. S., 1968: Role of a tropical "maritime continent" in the atmospheric circulation. Mon. Wea. Rev., 96, 365-370.

Ropelewski, C.F. and M.S. halpert, 1987, 1987 : Global and Regional Scale Precipitation parttern Associated with the El Nino/Southern Oscillation, Mon, Wea. Rev., 115, 1606-1628.

Seto. T.H., 2002 : Pengamatan Osilasi Madden Julian dengan Radar atmoefer Equator (EAR) di Bukittinggi Sumatera Barat (Sebuah Studi Pendahuluan), Jurnal Sains dan Teknologi Modifikasi Cuaca, Vol. 3, No. 2, p. 121-124. 